\title{
Effect of Washing and Cooking on Nitrate Content of Potatoes (cv. Diamant) and Implications for Mitigating Human Health Risk in Iran
}

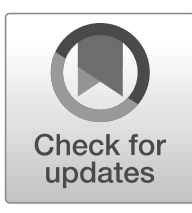

\section{Roya Ebrahimi, et al. [full author details at the end of the article]}

Received: 31 August 2019 / Accepted: 8 January 2020/

Published online: 10 February 2020

(C) European Association for Potato Research 2020

\begin{abstract}
The nitrite and nitrate in foodstuff and their associated harmful effects are of great concern for human health. More than $80 \%$ of human nitrate intake is attributed to the consumption of vegetables and fruits, and for this reason, more attention should be paid to the consumption of such foodstuffs and reduction of nitrate intake. Therefore, this study aimed to determine the variation of nitrate and nitrite content in potato during home preparation, process, and cooking methods, and assessed their health risk in different age groups for the first time in Iran. The nitrite content in all of the samples was lower than the apparatus detection limit so results are reported for nitrate. A total of 471 tubers of potato cultivar Diamant were assessed. The nitrate content was measured based on the tuber weight and also in different parts of potato. The impact of different washing and baking methods on nitrate contents were also assessed. Ion chromatography was employed to determine the nitrate content. The US Environmental Protection Agency (EPA) method covering the determination of nitrate in food was used to assess the health risk associated with potato consumption. The results showed that the average nitrate content was $123.26 \mathrm{mg} / \mathrm{kg}$ which was lower than the safe limit of nitrate. The results also showed that the total amount of nitrate in potato peel was $35 \%$ higher than in its central parts. Different washing methods could reduce the nitrate amount by 7.79 to $14.73 \%$. Boiling potato could significantly reduce the amount of nitrate by $59.7 \%$, while frying increased it by $52 \%$. There were significant differences among different potato cooking methods in terms of changes in the nitrate content $(P<0.001)$. This means that exposure in all age groups was less than the standard limits and potato intake was considered safe to all age groups. As there were significant changes in the nitrate content, it was concluded that washing and cooking methods, except frying, were suitable methods to reduce nitrate intake.
\end{abstract}

Keywords Cooking method $\cdot$ Health risk $\cdot$ Nitrate content of potatoes $\cdot$ Washing method

\section{Introduction}

Nitrates and nitrites are naturally found in the environment and their consumption via foodstuff in excessive amounts is harmful and can be a threat to human health 


\section{Affiliations}

Roya Ebrahimi ${ }^{1}$ - Afsaneh Ahmadian ${ }^{1}$ - Afsaneh Ferdousi ${ }^{1} \cdot$ Shiva Zandi $^{1}$. Behzad Shahmoradi ${ }^{1} \cdot$ Reza Ghanbari $^{2} \cdot$ Shadieh Mahammadi $^{1} \cdot$ Reza Rezaee $^{1}$. Mahdi Safari ${ }^{1} \cdot$ Hiua Daraei $^{1} \cdot$ Afshin Maleki $^{1} \cdot$ Kaan Yetilmezsoy $^{3}$

Afshin Maleki

maleki43@yahoo.com; malaki@muk.ac.ir

$\triangle$ Kaan Yetilmezsoy

yetilmez@yildiz.edu.tr; kyetilmezsoy@gmail.com

Roya Ebrahimi

ebrahimi83@yahoo.com

Afsaneh Ahmadian

aahmadian71@gmail.com

Afsaneh Ferdousi

afsane.ferdosi@gmail.com

Shiva Zandi

sh_rainbowz@yahoo.com

Behzad Shahmoradi

bshahmorady@gmail.com

Reza Ghanbari

ghanbari33@gmail.com

Shadieh Mahammadi

shadiehmohammadi@yahoo.com

Reza Rezaee

rezaee.eng@gmail.com; rezaee.r@muk.ac.ir

Mahdi Safari

safari.m.eng@gmail.com

Hiua Daraei

hiua.daraei@gmail.com

1 Environmental Health Research Center, Research Institute for Health Development, Kurdistan University of Medical Sciences, Sanandaj, Iran

2 Social Determinants of Health Research Center, Qazvin University of Medical Sciences, Qazvin, Iran

3 Department of Environmental Engineering, Faculty of Civil Engineering, Yildiz Technical University, Davutpasa Campus, Esenler, 34220 Istanbul, Turkey 